\title{
Novel self-assembled isonicotinic acid derivative and zinc porphyrin dyads and applications in dye sensitized solar cells
}

Yu Wu ( $\nabla$ emm_110177@126.com )

Qiannan Normal University for Nationalities

Qiumin Wang

Qiannan Normal University for Nationalities

Fang Wang

Qiannan Normal University for Nationalities

Mei Cheng

Qiannan Normal University for Nationalities

Jiacheng Liu

Northwest Normal University

Renzhi Li

Nanjing Tech University (Nanjing Tech)

\section{Research Article}

Keywords: dye-sensitized solar cells, zinc porphyrin, axial coordination, anchoring molecule

Posted Date: January 19th, 2022

DOI: https://doi.org/10.21203/rs.3.rs-1263423/v1

License: () (1) This work is licensed under a Creative Commons Attribution 4.0 International License.

Read Full License 


\section{Abstract}

A new self-assemblies based on double-deck dyes ZnTPP-Wi $(i=1-3)$ were synthesized and applied in dyesensitized solar cells (DSSCs). Anchoring molecules (Wi $i=1-3$ ) consisting of phenyl carboxyl acid and cyanoacetic acid group. Capping layer dyes ZnTPP with anchoring molecules formed dyads by the coordination bonds of $\mathrm{Zn}$-to-ligand self-assemblies solar cells devices. We herein report a consisting acylamide and cyanoacetic acid group W3 as an anchoring molecule for the axial coordination with upper zinc porphyrin ZnTPP. W3 was synthesized by introducing acylamide and cyanoacetic acid groups may inhibit adverse dye aggregation and improving electrons are effectively injected into the $\mathrm{TiO}_{2}$ semiconductor surface. Thus, W3 anchoring molecules can be used to fabricate efficient solar cells with ZnTPP porohyrin dye, achieving good photoelectric performance, indicative of their general applicability in fabricating good-performance DSSCs. The assembled modes were also verified by transmission electron microscopy (TEM). The photoelectrochemical efficiencies for dye ZnTPP-W3 are best than those of self-assembly dyes prevailingly ascribed to larger $J_{s c}$ and $V_{o c}$

\section{Introduction}

With the great progress Dye--sensitized solar cells (DSSCs) has made in the last three decades, have attracted much attention due to their supramolecular photosynthetic architectures to mimic the photoinduced energy and electron transfer processes ${ }^{1-5}$. A typical DSSC device consists of a photoanode, a counter electrode, electrolyte, and a dye for light harvesting. Photosensitizers as one of the main components in DSSCs have been well explored. Porphyrins have a broad absorption bands ${ }^{6-9}$ and high molar extinction coefficients ${ }^{10-14}$ also can serve as efficient sensitizers for DSSCs. To improve the light-harvesting ability of the porphyrin sensitizers is to use an electron donor (D) and electron acceptor (A) group, connected via $\pi$ bridge, construct $D-\pi-A$ structure ${ }^{15}$. Commonly used as electron acceptor groups such as carboxy $\left.\right|^{16}$, cyanoacrylic acid ${ }^{17}$, salicylic acid ${ }^{18}$ and so on. The better electron acceptor groups have also become promising candidates for DSSCs with excellent performance. Although D- $\pi-A$ zinc porphyrin has many advantages, its development is limited due to its complex structure, difficult synthesis process and low yields.

Porphyrin-based axial coordination self-assemblies, can afford a convenient method for designing and synthesizing of more efficient DSSCs. Utilization of axial metal-ligand coordination construct porphyrinbased donor-acceptor supramolecular assemblies with remarkable photovoltaic performance ${ }^{19-21}$. In this type of assemblies, the porphyrin center metal ion as ligand coordinated with anchoring molecule as electron acceptor ${ }^{20-21}$. D'Souza et al. reported a metal-ligand axial coordination approach to construct a series of (donor) $)_{1}$-(donor) ${ }_{2}$ porphyrin-based assemblies, its fully proved that this self-assembly can effectively realize photoelectric transfer ${ }^{22}$. Therefore, such as assemblies are widely applied in photovoltaic devices ${ }^{23-25}$. 
In this paper, three anchored molecules featuring carboxyl and cyanoacrylic acid groups as electron acceptor have been designed and synthesized (denoted as Wi i=1-3, shown in Scheme 1). Three anchored molecules and zinc meso-tetraphenyl porphyrin (denoted as ZnTPP, shown in Scheme 1) construct axialcoordinated assemblies (described as ZnTPP-Wi, i=1-3) solar cells. The optical properties, topography, theoretical calculations and the photovoltaic performances of the assemblies are studied to further understand the behavior of the ZnTPP-Wi based dye-sensitized solar cells.

The assembled processes of $\mathbf{Z n T P P}-W i$ on $\mathrm{TiO}_{2}$ surface are as follows: an anchoring molecule (Wi) was immobilized on the $\mathrm{TiO}_{2}$ electrode surface through carboxylic groups, then the desired dye of ZnTPP was bound to the anchoring group through axially coordination bonded from porphyrin central $\mathrm{Zn}(\mathrm{II})$ ions of ZnTPP and the $\mathrm{N}$ atom of Wi. The detailed assembly approach is shown in Scheme 2.

\section{Experimental}

\subsection{Materials and physical measurements}

All solvents and reagents were used directly without further purification as commercially analytical grade. Isonicotinic acid and 4-pyridylcarboxyaldehyde were purchased from Aldrich, pyrrole was distilled prior to use. Electronic absorption spectra were measured on a UV-2550 spectrometer. $1 \mathrm{H} \mathrm{NMR}(400 \mathrm{MHz})$ was measured on a Varian Mercury Plus-400 spectrometer. Electrospray ionization (ESI) mass spectra was investigated on a Thermo Fisher-QE mass spectrometer. Surface topography of the self-assembly films on $\mathrm{TiO}_{2}$ electrode surface was imaged using transmission electron microscopy (TEM) (Hitachi Model H900). The electrochemical impedance spectroscopy (EIS) was achieved on a Princeton applied research VMP2 multi potentiate. The detail synthesis processes are shown in Scheme 3.

\subsection{Synthesis}

The synthesis of $\mathrm{W} 1$

A similar method was previously reported ${ }^{26}$. A mixture of isonicotinic acid $(2.46 \mathrm{~g}, 20 \mathrm{mmol})$ and $\mathrm{SOCl}_{2}$ $(20 \mathrm{~mL})$ was refluxed for 2 hours then excess $\mathrm{SOCl}_{2}$ was removed under vacuum. The residue was dissolved in dry dichloromethane $(40 \mathrm{~mL})$. To the solution was added 4 -aminobenzoic acid $(2.74 \mathrm{~g}, 20$ $\mathrm{mmol})$ and then triethylamine $(5.6 \mathrm{~mL}, 40 \mathrm{mmol})$. The reaction mixture was stirred overnight at ambient temperature and dichloromethane was removed by rotary evaporation, the solid then dissolved in $5 \%$ $\mathrm{NaOH}$ followed by slowly acidified with conc. $\mathrm{HCl}$. Precipitate appears and filtered, washed with water and dried to give $\mathrm{W} 1$ as a light yellow solid. Yield, 63.2\% 1H NMR $\left(\mathrm{CDCl}_{3}\right) \delta 10.1$ (s 1H), 8.82 (d, 2H), 7.85$8.13(\mathrm{dd}, 6 \mathrm{H}) \mathrm{HRMS}(\mathrm{ESI}, \mathrm{m} / \mathrm{z}):\left[\mathrm{M}+\mathrm{H}^{+}\right.$calcd for $\mathrm{C}_{13} \mathrm{H}_{10} \mathrm{~N}_{2} \mathrm{O}_{3}, 243.0$; found 243.23.

The synthesis of $\mathrm{W} 2$

A similar method was previously reported ${ }^{24}$. Yield, 63.2\% $1 \mathrm{H} \mathrm{NMR}\left(\mathrm{CDCl}_{3}\right) \delta 8.78-8.80(\mathrm{~d} 2 \mathrm{H}), 8.35(\mathrm{~s}, 1 \mathrm{H})$, 7.83-7.85 (dd, 2H) HRMS (ESI, m/z): [M + H] $]^{+}$calcd for $\mathrm{C}_{9} \mathrm{H}_{6} \mathrm{~N}_{2} \mathrm{O}_{2}, 175.0$; found 175.05 . 
c was synthesized in a similar procedure as A3 except that 4-aminobenzoic acid was replaced by 4aminophenol $(2.18 \mathrm{~g}, 20 \mathrm{mmol})$, $\mathrm{c}$ in $\mathrm{CH}_{3} \mathrm{OH}(5 \mathrm{~mL})$ then cyanoacetic acid $(0.065 \mathrm{mmol}, 5.5 \mathrm{~g})$, was dissolved in $\mathrm{CH}_{3} \mathrm{OH}(10 \mathrm{~mL})$ was added under magnetic stirring. The mixture was reacted at ambient temperature for 3 hours. White precipitated generated and was filtered off, washed by $\mathrm{CH}_{3} \mathrm{OH}$ to give W3 as a white powder in 58.3\% yield. $1 \mathrm{H}$ NMR (DMSO) $\delta 10.80$ (s 1H), 9.02-9.03 (d, 2H), 8.36-8.38 (d, 2H), 7.57-7.59 (d, 2H), 6.76-6.79 (d, 2H) HRMS (ESI, m/z): [M + H] ${ }^{+}$calcd for $\mathrm{C}_{16} \mathrm{H}_{11} \mathrm{~N}_{3} \mathrm{O}_{3}, 294.0$; found 294.08.

The synthesis of ZnTPP

A similar method was previously reported. Yield, 27.2\% 1H NMR (DMSO) $\delta 8.75$ (s 2H), 8.15-8.17 (m, 2H), 7.78-7.79 (m, 2H), $5.74(\mathrm{~s}, 1 \mathrm{H}), 3.31(\mathrm{~s}, 2 \mathrm{H}), 1.21(\mathrm{~s}, 1 \mathrm{H}) \mathrm{HRMS}(\mathrm{ESI}, \mathrm{m} / \mathrm{z}):[\mathrm{M}+\mathrm{H}]^{+}$calcd for $\mathrm{C}_{44} \mathrm{H}_{28} \mathrm{~N}_{4} \mathrm{Zn}$, 677.0; found 677.16.

\subsection{Device fabrication}

The detailed preparation procedures of $\mathrm{TiO}_{2}$ nanocrystals, pastes for screen-printing, and nanostructured $\mathrm{TiO}_{2}$ film have been reported by Prof. P. Wang ${ }^{27}$. A cycloidal $\mathrm{TiO}_{2}$ electrode $\left(\sim 0.28 \mathrm{~cm}^{2}\right)$ was stained by immersing it into a solution containing anchoring molecule $(2 \mathrm{mM})$ in DMF overnight, after removal of the unbound molecules (through three ethanol washings), then the electrode was immersed into a dye solution containing $\mathrm{ZnTPP}(0.2 \mathrm{mM})$ in $\mathrm{CHCl}_{3} / \mathrm{CH}_{3} \mathrm{OH}$ for $2 \mathrm{~h}$, then, washed by acetonitrile solution three times and dried by air flow. The sensitized titania electrode was assembled with a thermally platinized FTO electrode. The electrodes were separated by a 35- $\mu$ m-thick Bynel (DuPont) hot-melt gasket and sealed up by heating. The internal space was filled with a liquid electrolyte using a vacuum backfilling system. The electrolyte-injecting hole on the counter electrode glass substrate, made with a sand-blasting drill, was sealed with a Bynel sheet and a thin glass cover by heating. The electrolyte used contained 50 $\mathrm{mM} \mathrm{Lil,} 30 \mathrm{mM} \mathrm{I}_{2}$ in acetonitrile solvent. After all these procedures, the cells were located in the oven for heating posttreatment at $100^{\circ} \mathrm{C}$ for $30 \mathrm{~min}$ and cooled to room temperature before photoelectrochemical measurements.

\section{Results And Discussion}

\subsection{Photophysical properties}

The UV-vis absorption spectra for ZnTPP dye in $\mathrm{CHCl}_{3}$ solution, the assembled dyes (ZnTPP-Wi i=1-3) absorbed onto $\mathrm{TiO}_{2}$ films are displayed in Fig. 1 and the data are summarized in Table S1. In general, all these dyes have two absorption bands at ca. $400-450 \mathrm{~nm}$ and ca. 550-650nm, corresponding to typical porphyrin spectra. Compared with the absorption spectrum of $\mathrm{ZnTPP}$ in $\mathrm{CHCl}_{3}$, the assembled dyes ZnTPP-Wi corresponding spectrum on the $\mathrm{TiO}_{2}$ film is slightly broadened and red shifted, which may be 
related to the $\mathrm{J}$-aggregation of the assembled dye molecules on the $\mathrm{TiO}_{2}$ film ${ }^{28,29}$. These characters are favorable for enhancing the light-harvesting ability.

The light harvesting efficiency (LHE) will quantify this capability of a device to absorb photons, as LHE $(\lambda)$ is the incident light-harvesting efficiency for photons with wavelength $\lambda(n m),\left(L H E=\left(1-10^{-A}\right)\right.$, with $A$ being the absorbance of the film ${ }^{30}$. As all films display very similar absorption spectra (Fig. 1), LHE were assumed likewise to be similar for all dyes, but on the other hand, cyanoacetic acid group can expect that it would favorably improve the LHE of the dye. As Fig. 2, indeed, going from ZnTPP-W2 and ZnTPP-W3, the introduction of cyanoacetic acid anchoring group causes assembled systematic important redshifts and broadening. For ZnTPP-W3 has a higher LHE, which is the key factor for higher short circuit current density $\left(J_{s c}\right)$.

\subsection{Density functional theory (DFT) calculations}

The energy-optimized structures, electronic distribution, and energy levels of HOMO-LUMO of all three self-assemblies dyes were theoretically calculated using the Gaussian 09 program package with the functional basis set of the B3LYP/6-31 G level ${ }^{31,32}$. As can be seen from Fig. 3, the HOMOs for three selfassemblies dyes (ZnTPP-Wi) are completely located on the top porphyrin cores and the LUMO is delocalized over the bottom anchoring molecules respectively, which is very important for efficient electron injection from the excited state of the sensitizer to the conduction band of the $\mathrm{TiO}_{2}$ semiconductor. The HOMO energy levels of all dyes are almost at $0.35 \mathrm{~V}$ owing to the presence of the same top porphyrin molecular structures. These values are more negative than the redox potential of the $\mathrm{I}^{-} / \mathrm{I}_{3}{ }^{-}$couple $(-4.60 \mathrm{eV})$, assuring sufficient dye regeneration ${ }^{33}$. The LUMO values of the dyes are also slightly more positive than the conduction band of $\mathrm{TiO}_{2}(-4.00 \mathrm{eV})$, resulting in a diminished driving force for charge injection into $\mathrm{TiO}_{2}{ }^{34,35}$. The HOMO-LUMO gap of the three sensitizers are $2.46 \mathrm{eV}$ (ZnTPP-W1), $2.17 \mathrm{eV}$ (ZnTPP-W2) and $2.02 \mathrm{eV}$ (ZnTPP-W3), and the order is ZnTPP-W1> ZnTPP-W2> ZnTPP-W3.

\subsection{Morphological characterization}

The surface morphologies of ZnTPP-Wi $(\mathrm{i}=1-3)$ sensitized on the $\mathrm{TiO}_{2}$ electrode surfaces were performed using transmission electron microscopy (TEM), the characteristic method well-established by some other researchers ${ }^{36,37}$. With respect to the comparison of the length of two ends of the dyad obtained by computational simulation (Fig. S1) and the film thickness identified under TEM analysis (Fig. 4). The film thicknesses almost match to the computational values, indicating that the assemble modes of ZnTPP-Wi immobilized onto the $\mathrm{TiO}_{2}$ electrode surfaces should be similar to those of Scheme 2 .

\subsection{Photovoltaic properties}

The photovoltaic performance of DSSCs using an iodine electrolyte under standard AM 1.5 irradiation $\left(100 \mathrm{~mW} \mathrm{~cm}^{-2}\right)$. The photocurrent density-voltage $(\mathrm{J}-V)$ curves of the devices and the detailed performance parameters are given in Fig. 5 and Table S2, respectively. The short-circuit current density $\left(J_{s c}\right)$ decreased in order ZnTPP-W3 $\left(3.69 \mathrm{~mA} / \mathrm{cm}^{2}\right)>$ ZnTPP-W2 $\left(2.78 \mathrm{~mA} / \mathrm{cm}^{2}\right)>$ ZnTPP-W1 $(2.65 \mathrm{~mA}$ 
$\left./ \mathrm{cm}^{2}\right)$, which indicated that the presence of the cyanoacetic acid anchoring group had a significant effect on electron injection. The open-circuit voltage $\left(V_{o c}\right)$ of the devices decreased in the order ZnTPPW3 $(0.41 \mathrm{~V})>$ ZnTPP-W2 $(0.37 \mathrm{~V})>$ ZnTPP-W1 $(0.35 \mathrm{~V})$, which the ZnTPP-W3 device exhibited a higher power conversion efficiency. By comparing these photovoltaic parameters and analyzing anchor molecular structure, we can ZnTPP-W3 device, has strong electron injection ability of the conclude cyanoacetic acid group and longer molecular structure can effectively inhibit the electron aggregation between the upper porphyrin and $\mathrm{TiO}_{2}$ surface.

The incident photon-current conversion efficiencies (IPCEs) for these dyes in DSSCs are plotted in Fig. 6. All dyes exhibited broad optical response range from 350 to $700 \mathrm{~nm}$, which maximum IPCE peaks of $45 \%$ for ZnTPP-W1, and 47\% for ZnTPP-W2, and 76\% for ZnTPP-W3. ZnTPP-W3 exhibited stronger absorption response, whose DSC device possessed outstanding light capturing ability and then obtained higher $J_{s c}$ value. The IPCE response of ZnTPP-W1 was lower, which is attributed to the conventional anchor group of benzoic acid. Therefore, the cyanoacetic acid anchor group of ZnTPP-W3 improved its light harvesting ability, which resulted in improved current density.

APCE is the absorbed photo to current conversion efficiency and shows how efficient the numbers of absorbed photons are converted into current ${ }^{16,30}$. APCE values provide further insight into the properties of the device, which originates by dividing the IPCE number by the LHE and the results are depicted in Fig. S2. The maximum APCE value, decreases in the order ZnTPP-W3 (85\%) > ZnTPP-W2 (55\%) > ZnTPP-W1 (50\%). Thus, the superior performance of ZnTPP-W3 cell, mainly arises from the relative larger integrated APCE value.

\subsection{Electrochemical impedance spectroscopy analysis}

The electrochemical impedance spectroscopy (EIS) under dark was often measured to study the electron recombination dynamics of the DSSCs, electron recombination rate has an important influence on the open-circuit voltage $\left(V_{o c}\right)$, we measured the EIS under the applied voltage of $-0.6 \mathrm{~V}^{38-41}$. The equivalent circuit was presented in Fig. $7 c, R_{S}, R_{C T}, R_{\text {ele }}$ and $C$ represent series resistances, charge transfer resistances, Nernst diffusion resistances and double layer capacitance, respectively. Nyquist plots of DSSCs are shown in Fig. 7a, the larger semicircle at the intermediated frequency reflected the charge transfer resistance $\left(\mathrm{R}_{\mathrm{ct}}\right)$ at the $\mathrm{TiO}_{2} /$ dye/electrolyte interface. It is clear that radius of the large semicircle of ZnTPP-W3 is largest than that of other cell devices. It indicates tant the cyanoacetic acid group is effective in $\mathrm{TiO}_{2}$ /dye/electrolyte interface modification, and this implies that the cyanoacetic acid effectively reduces the electron recombination rate, giving rise to a higher $V_{o c}{ }^{42,43}$. In generally, a high charge transfer resistance will lead to a long electron lifetime. We analyzed the electron lifetimes of the devices by bode phase plots (Fig. 7b). The electron lifetime ( $\tau$ ) can be calculated by $\tau=1 /(2 \pi f)^{44,45}$. The bode phase plots show that ZnTPP-W3 based device have longest electron lifetime compared to other cells. This is explaining the DSSCs based on ZnTPP-W3 has the highest $V_{o C}$.

\section{Conclusion}


In this work, we report the synthesis, fundamental properties, and photovoltaic performance in DSSC of three new anchoring molecules (Wi, $\mathrm{i}=1-3)$ and zinc meso-tetraphenylporphine (ZnTPP). A novel type assembly based on ZnTPP appended anchoring molecules ( $\mathrm{Wi}, \mathrm{i}=1-3)$ via metal-ligand axial coordination and modified the nano-structured $\mathrm{TiO}_{2}$ electrode surface. The photovoltaic properties studies show that ZnTPP-W3 outperforms others in the series with a PCE of 1.15\%. Superior PCE of ZnTPP-W3 may be attributed to the greater $J_{s c}$ and $V_{o c}$ values. A greater $J_{s c}$ is consistent with a broadened and red-shifted spectrum with cyanoacetic acid group and longer molecular structure. EIS measurements suggest that the higher $V_{o c}$ of the ZnTPP-W3 cell may be attributed to a greater charge recombination resistance. As to remedy the possible issue of high-performance self-assembly cells, synthesis of more suitable for molecular structure.

\section{Declarations}

\section{Acknowledgments}

The National Natural Science Foundation of China (No. 21461023); Guizhou Province Science Foundation (QianKeHe-ZK[2021]064); Natural Science Foundation of Guizhou Education Department (QianJiaoHe KY Zi [2020]200; [2020]203) and Major projects of research and Innovation Fund of Qiannan Normal University for Nationalities (No. QNSY2018BS020) have supported this work. We are very grateful to Prof. Peng Wang (Changchun Institute of Applied Chemistry, Chinese Academy of Sciences) for supplying device fabrication and measurement of solar cells. We also acknowledge the support of Key Laboratory of Computational Catalytic Chemistry of Guizhou Province. The authors also thank Shiyanjia Lab (www.shiyanjia.com) for the HRMS and 1H NMR measurement and analysis.

\section{References}

1. F. D'Souza, A.N. Amin, M.E. El-Khouly et al., Control over photoinduced energy and electron transfer in supramolecular polyads of covalently linked azaBODIPY-bisporphyrin 'molecular clip' hosting fullerene[J]. J 134, 654-664 (2012) A C Soc,

2. I. Takahiko, M. Yutaka, N. Eiichi, Photostability of a dyad of magnesium porphyrin and fullerene and its application to photocurrent conversion[J]. Chem 49, 279-281 (2013) Commun .,

3. H. Zhou, L. Yang, A.C. Stuart et al., Development of Fluorinated Benzothiadiazole as a Structural Unit for a Polymer Solar Cell of 7\%. Efficiency[J]. Angew 50, 2995-2998 (2011) C I Ed .,

4. F.C. Krebs, T. Thomas, J. Mikkel, Upscaling of polymer solar cell fabrication using full roll-to-roll processing[J]. Nanoscale<bi>,</bi> 2, 873-886 (2010)

5. K. Yu, J. Chen, Enhancing Solar Cell Efficiencies through 1-D Nanostructures[J]. Nanoscale Res 4, 110 (2009) Lett .,

6. G. Su, Q. Li, M. Ishida et al., N-Confused Phlorin-Prodigiosin Chimera: meso-Aryl Oxidation and $\pi-$ Extension Triggered by Peripheral Coordination[J]. Angew. Chem. Int. Ed. 59(4), 1537-1541 (2020) 
7. N. Zarrabi, S. Seetharaman, S. Chaudhuri et al., Decelerating Charge Recombination Using Fluorinated Porphyrins in N, N-Bis (3, 4, 5-trimethoxyphenyl) aniline-Aluminum (III) PorphyrinFullerene Reaction Center Models[J]. J 142(22), 10008-10024 (2020) A C Soc, (

8. N. Jiang, Y. Wang, A. Qin et al., Effective enhancement of the emission efficiency of tetraphenylporphyrin in solid state by tetraphenylethene modification[J]. Chinese Chem. Lett. 30(1), 143-148 (2019)

9. W. Miao, Z. Zhu, Z. Li et al., Novel expanded porphyrinoids with multiple-inner-ring-fusion and/or tunable aromaticity[J]. Chinese Chem. Lett. 30(11), 1895-1902 (2019)

10. Y. Tang, X. Liu, Y. Wang et al., Solar cells sensitized by porphyrin dyes containing a substituted carbazole donor with synergistically extended absorption and suppressed the dye aggregation[J]. Chinese Chem. Lett. 31(7), 1927-1930 (2020)

11. Y. Hu, W.A. Webre, M.B. Thomas et al., $\beta$-Functionalized push-pull opp-dibenzoporphyrins as sensitizers for dye-sensitized solar cells: the role of the phenylethynyl bridge[J]. J. Mater. Chem. A 7(17), 10712-10722 (2019)

12. Y. Chen, K. Zeng, C. Li et al., A new type of multibenzyloxy-wrapped porphyrin sensitizers for developing efficient dye-sensitized solar cells[J]. J. Porphyrins Phthalocya. 24, 401-409 (2020)

13. Y. Lu, Y. Cheng, C. Li et al., Efficient solar cells based on cosensitizing porphyrin dyes containing a wrapped donor, a wrapped $\pi$-framework and a substituted benzothiadiazole unit[J]. Sci. China Chem. 62(8), 994-1000 (2019)

14. K. Zeng, Y. Lu, W. Tang et al., Efficient solar cells sensitized by a promising new type of porphyrin: dye-aggregation suppressed by double strapping[J]. Chem. Sci. 10(7), 2186-2192 (2019)

15. C.W. Lee, H.P. Lu, C.M. Lan et al., Novel zinc porphyrin sensitizers for dye-sensitized solar cells: synthesis and spectral, electrochemical, and photovoltaic properties[J]. Chem.-Eur. J. 15(6), 14031412 (2009)

16. A. Hagfeldt, G. Boschloo, L. Sun et al., Dye-sensitized solar cells[J]. Chem. Rev. 110(11), 6595-6663 (2010)

17. T. Wei, X. Sun, X. Li et al., Systematic investigations on the roles of the electron acceptor and neighboring ethynylene moiety in porphyrins for dye-sensitized solar cells[J]. ACS Appl. Mater. Inter. 7(39), 21956-21965 (2015)

18. F. Gou, X. Jiang, R. Fang et al., Strategy to improve photovoltaic performance of DSSC sensitized by zinc prophyrin using salicylic acid as a tridentate anchoring group[J]. ACS Appl. Mater. Inter. 6(9), 6697-6703 (2014)

19. F. D'Souza, G.R. Deviprasad, M.E. Zandler et al., Spectroscopic, electrochemical, and photochemical studies of self-assembled via axial coordination zinc porphyrin-fulleropyrrolidine dyads[J]. J. Phys. Chem. A 106(13), 3243-3252 (2002)

20. T. Honda, T. Nakanishi, K. Ohkubo et al., Formation of a long-lived photoinduced electron-transfer state in an electron acceptor-donor-acceptor porphyrin triad connected by coordination bonds[J]. J. Phys. Chem. C 114(33), 14290-14299 (2010) 
21. J. Otsuki, M. Takatsuki, M. Kaneko et al., Formation of a supramolecular porphyrin-spacer-acceptor ternary complex and intracomplex electron transfer[J]. J. Phys. Chem. A 107(3), 379-385 (2003)

22. N.K. Subbaiyan, C.A. Wijesinghe, F. D'Souza, Supramolecular solar cells: surface modification of nanocrytalline $\mathrm{TiO}_{2}$ with coordinating ligands to immobilize sensitizers and dyads via metal-ligand coordination for enhanced photocurrent generation[J]. J 131(41), 14646-14647 (2009) A C Soc, (

23. Y. Wu, Q. Zhang, J.C. Liu et al., A novel self-assembly with two acetohydrazide zinc porphyrins coordination polymer for supramolecular solar cells[J]. Org. Electron. 41, 301-306 (2017)

24. J.X. Zhang, F.M. Han, J.C. Liu et al., Self-assemblies formed by isonicotinic acid analogues axially coordinating with zinc porphyrin via pyridyl unit: Synthesis and application in dye sensitized solar cells[J]. Tetrahedron Lett. 57(17), 1867-1872 (2016)

25. Y. Wu, J.C. Liu, J. Cao et al., Two self-assemblies of Schiff base porphyrins to modify titanium dioxide electrodes for supramolecular solar cells[J]. Res 41, 6833-6842 (2014) C Intermediat,

26. K.M. Wang, Y.C. Qin, G.J. Cheng et al., Design, Synthesis and Antibacterial Evaluation of Novel Fluoroquinolone and its Derivatives[J]. Asian J. Chem. 26(1), 209-215 (2014)

27. P. Wang, S.M. Zakeeruddin, P. Comte et al., Enhance the Performance of Dye-Sensitized Solar Cells by Co-grafting Amphiphilic Sensitizer and Hexadecylmalonic Acid on $\mathrm{TiO}_{2}$ Nanocrystals[J]. $\left.<\mathrm{bi}>\mathrm{J} .</ \mathrm{bi}\right\rangle$ Phys 107, 14336-14341 (2003) C B ,

28. J.M. Ji, H. Zhou, H.K. Kim, Rational design criteria for D-п-A structured organic and porphyrin sensitizers for highly efficient dye-sensitized solar cells[J]. J. of Mater. Chem. A, 2018, 6(30): 1451814545

29. B. Chen, L. Sun, Y.S. Xie, Modulation of photovoltaic behavior of dye-sensitized solar cells by electron donors of porphyrin dyes and cosensitization[J]. Chin. Chem. Lett. 26(7), 899-904 (2015)

30. M. Urbani, M. Grätzel, M.K. Nazeeruddin et al., Meso-substituted porphyrins for dye-sensitized solar cells[J]. Chem. Rev. 114(24), 12330-12396 (2014)

31. M.J. Frisch, G.W. Trucks, H.B. Schlegel et al., Gaussian 09, Revision a, 02 (Gaussian, Inc., Wallingford, CT, USA, 2009)

32. P.J. Hay, W.R. Wadt, Ab initio effective core potentials for molecular calculations. Potentials for the transition metal atoms Sc to Hg[J]. J. Chem. Phys. 82(1), 270-283 (1985)

33. W. Lee, S.B. Yuk, J. Choi et al., The effects of the number of anchoring groups and N-substitution on the performance of phenoxazine dyes in dye-sensitized solar cells[J]. Dyes Pigm. 102, 13-21 (2014)

34. L. Yu, W. Shi, L. Lin et al., Effects of benzo-annelation of asymmetric phthalocyanine on the photovoltaic performance of dye-sensitized solar cells[J]. Dalton Trans. 43(22), 8421-8430 (2014)

35. S. Soman, M.A. Rahim, S. Lingamoorthy et al., Strategies for optimizing the performance of carbazole thiophene appended unsymmetrical squaraine dyes for dye-sensitized solar cells[J]. Phys. Chem. Chem. Phys. 17(35), 23095-23103 (2015)

36. A. Kira, T. Umeyama, Y. Matano et al., Supramolecular donor-acceptor Heterojunctions by Vectorial stepwise assembly of Porphyrins and coordination-bonded fullerene arrays for photocurrent 
generation[J]. J. Am. Chem. Soc. 131(9), 3198-3200 (2009)

37. C. Yang, Z. Yang, H. Gu et al., Facet-selective 2D self-assembly of $\mathrm{TiO}_{2}$ nanoleaves via supramolecular interactions[J]. Chem. Mater. 20(24), 7514-7520 (2008)

38. H. Choi, Y.S. Chen, K.G. Stamplecoskie et al., Boosting the photovoltage of dye-sensitized solar cells with thiolated gold nanoclusters[J]. J. Phys. Chem. Lett. 6(1), 217-223 (2015)

39. Z.S. Wang, Y. Cui, K. Hara et al., A high-light-harvesting-efficiency coumarin dye for stable dyesensitized solar cells[J]. Adv. Mater. 19(8), 1138-1141 (2007)

40. A. O. Biroli, F. Tessore, V. Vece et al., Highly improved performance of Zn II tetraarylporphyrinates in DSSCs by the presence of octyloxy chains in the aryl rings[J]. J. Mater. Chem. A 3(6), 2954-2959 (2015)

41. C. Chen, X. Yang, M. Cheng et al., Efficient panchromatic organic sensitizers with dihydrothiazole derivative as $\pi$-bridge for dye-sensitized solar cells[J]. ACS Appl. Mater. Interfaces 5(21), 1096010965 (2013)

42. S. Bok Joo, S. Hae Min, In Taek C, et al. A desirable hole-conducting coadsorbent for highly efficient dye-sensitized solar cells through an organic redox cascade strategy[J]. $<$ bi $>C h e m$. - A Eur. J., </bi $>$ 2011, 17: 11115-11121

43. H.M. Song, D.S. Kang, S.K. Min et al., A simple triaryl amine-based dual functioned co-adsorbent for highly efficient dye-sensitized solar cells[J]. J 22, 3786-3794 (2012) M Chem .,

44. W. Zhang, Y. Wu, H. Zhu et al., Rational molecular engineering of indoline-based D-A- $\pi-A$ organic sensitizers for long-wavelength-responsive dye-sensitized solar cells[J]. ACS Appl. Mater. Interfaces 7(48), 26802-26810 (2015)

45. J.M. Andrés-Castán, S. Franco, B. Villacampa et al., New efficient tert-butyldiphenyl-4 H-pyranylidene sensitizers for DSSCs[J]. RSC adv., 2015, 5(129): 106706-106709

\section{Figures}




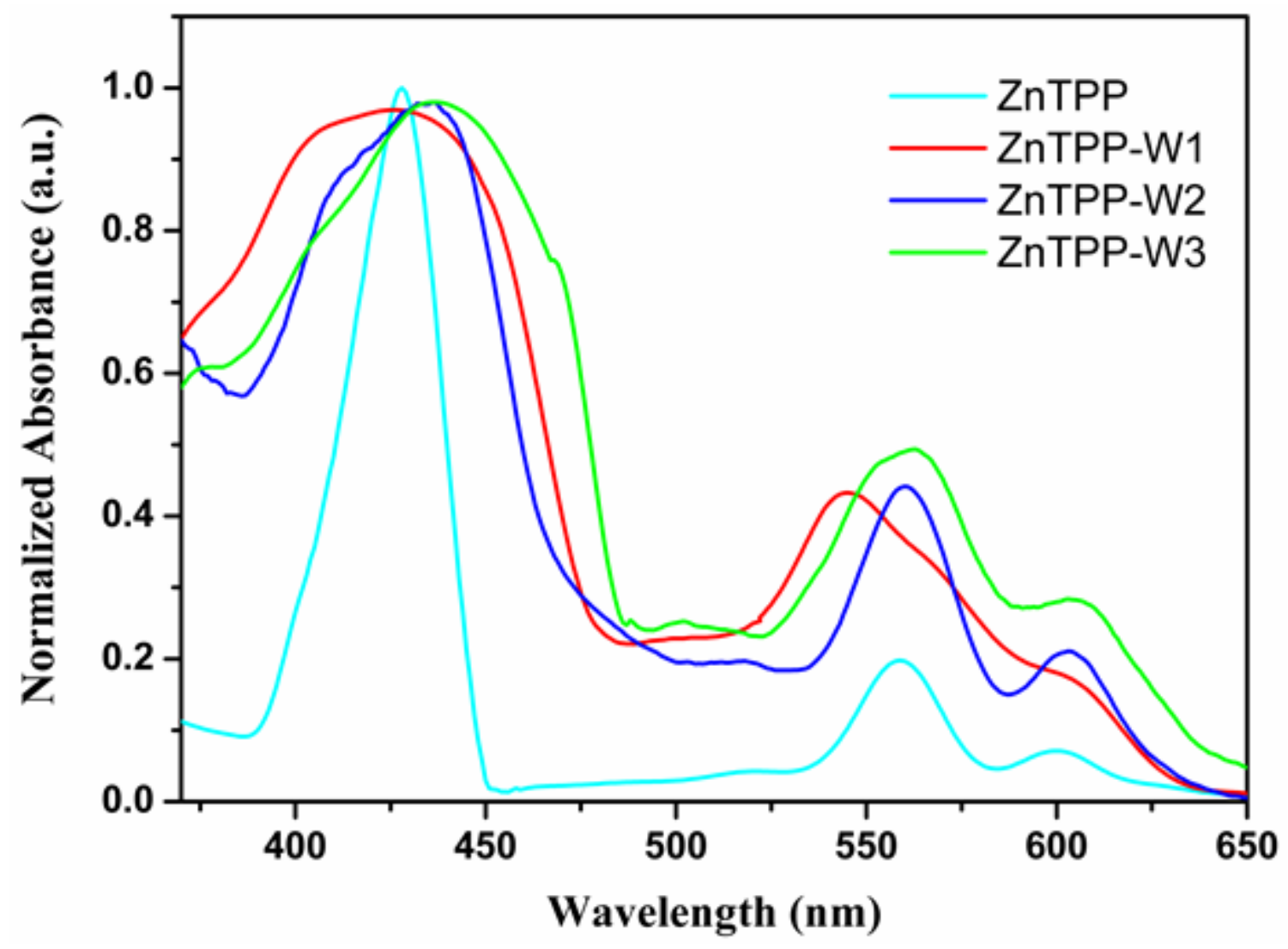

Figure 1

UV-Vis absorption spectra of $\mathbf{Z n T P P}$ in $\mathrm{CHCl}_{3}$ solution and $\mathbf{Z n T P P}-\mathbf{W i}$ on $\mathrm{TiO}_{2}$ thin films 


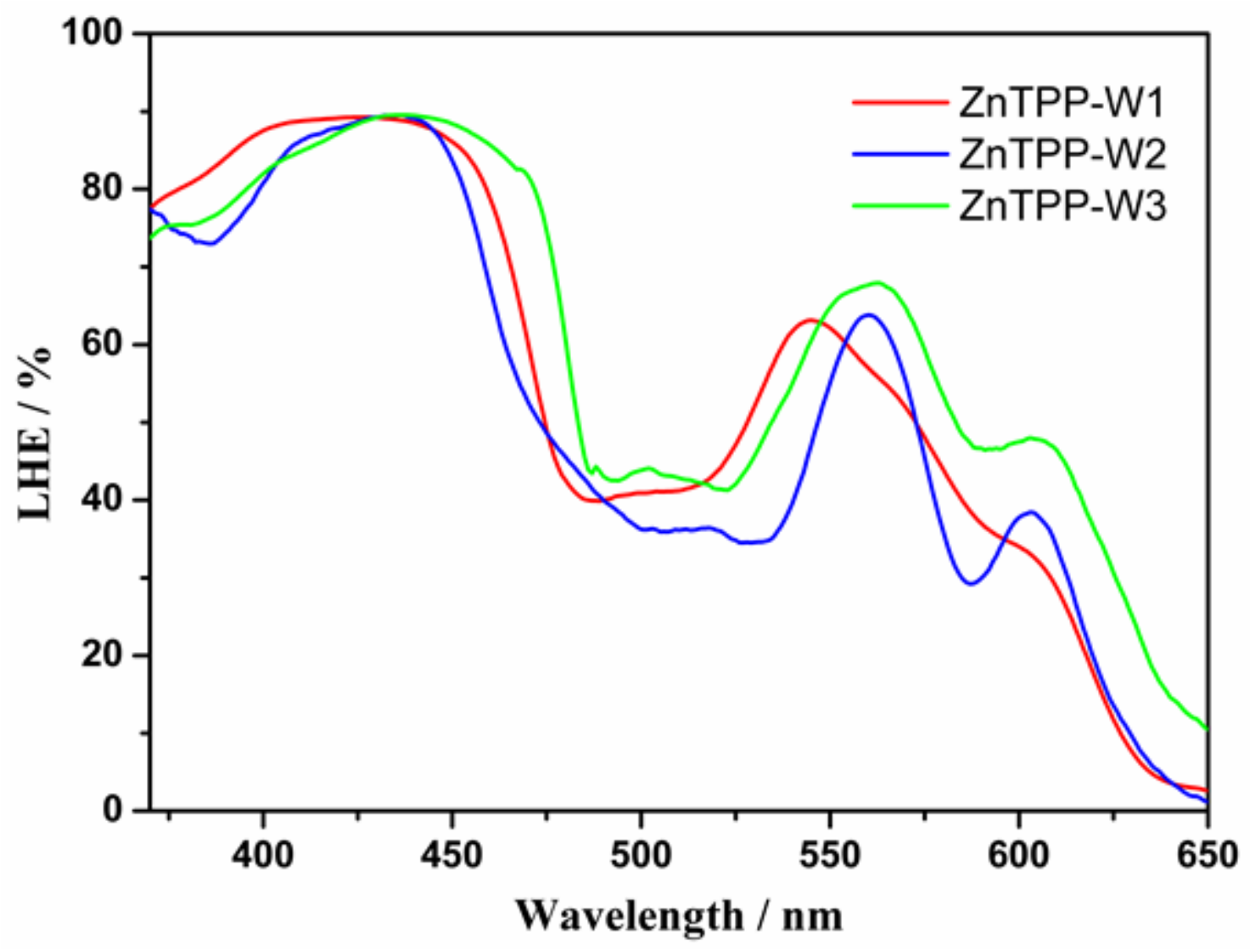

Figure 2

Light harvesting efficiency of the self-assemblies dyes $\mathrm{TiO}_{2}$ electrodes

Figure 3

Energy diagram of three assemblies dyes calculated using the B3LYP/6-31G level. 


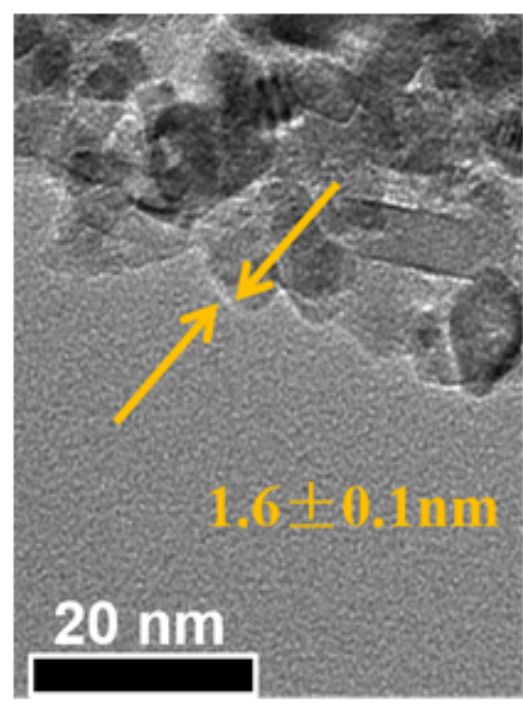

ZnTPP-W1

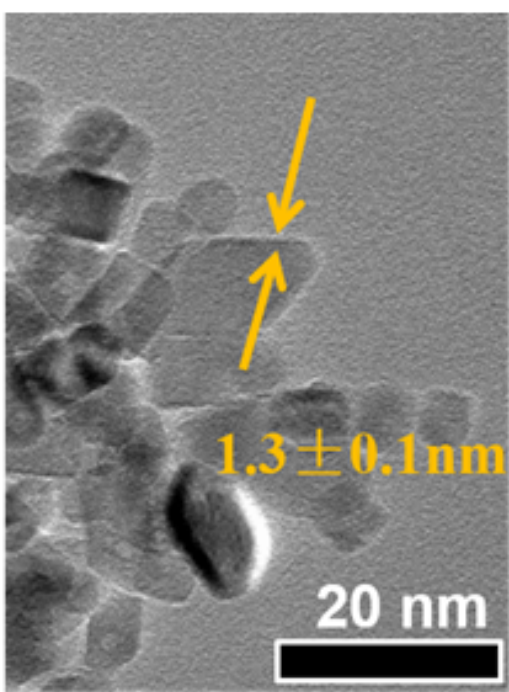

ZnTPP-W2

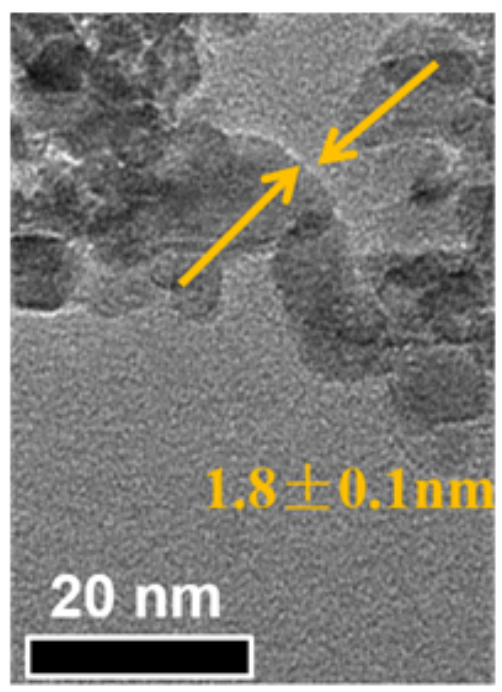

ZnTPP-W3

Figure 4

TEM images of $\mathrm{TiO}_{2}$ nanoparticles modified with ZnTPP-Wi $(i=1-3)$.

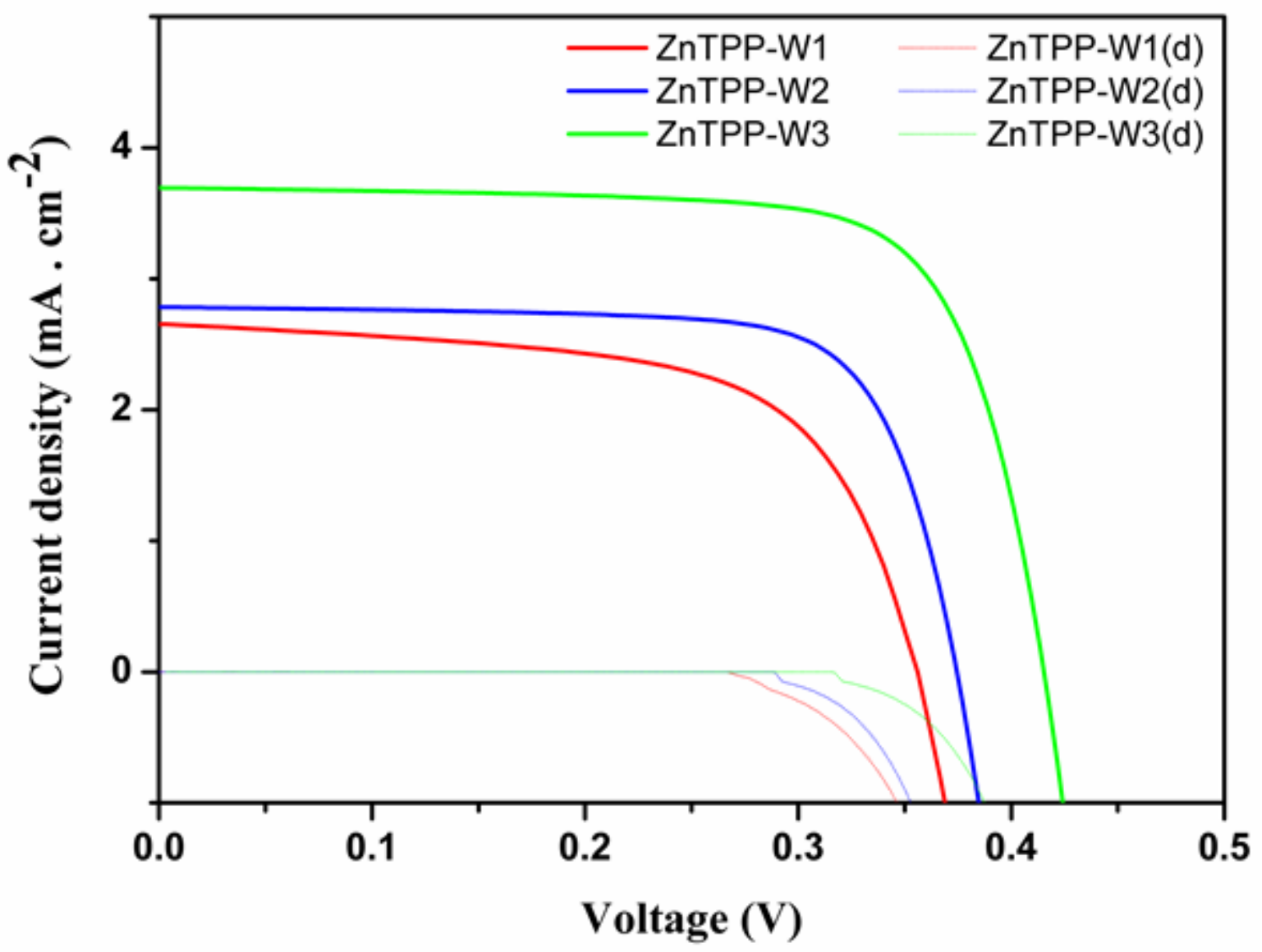


Figure 5

$J-V$ characteristics of ZnTPP-Wi (i=1-3).

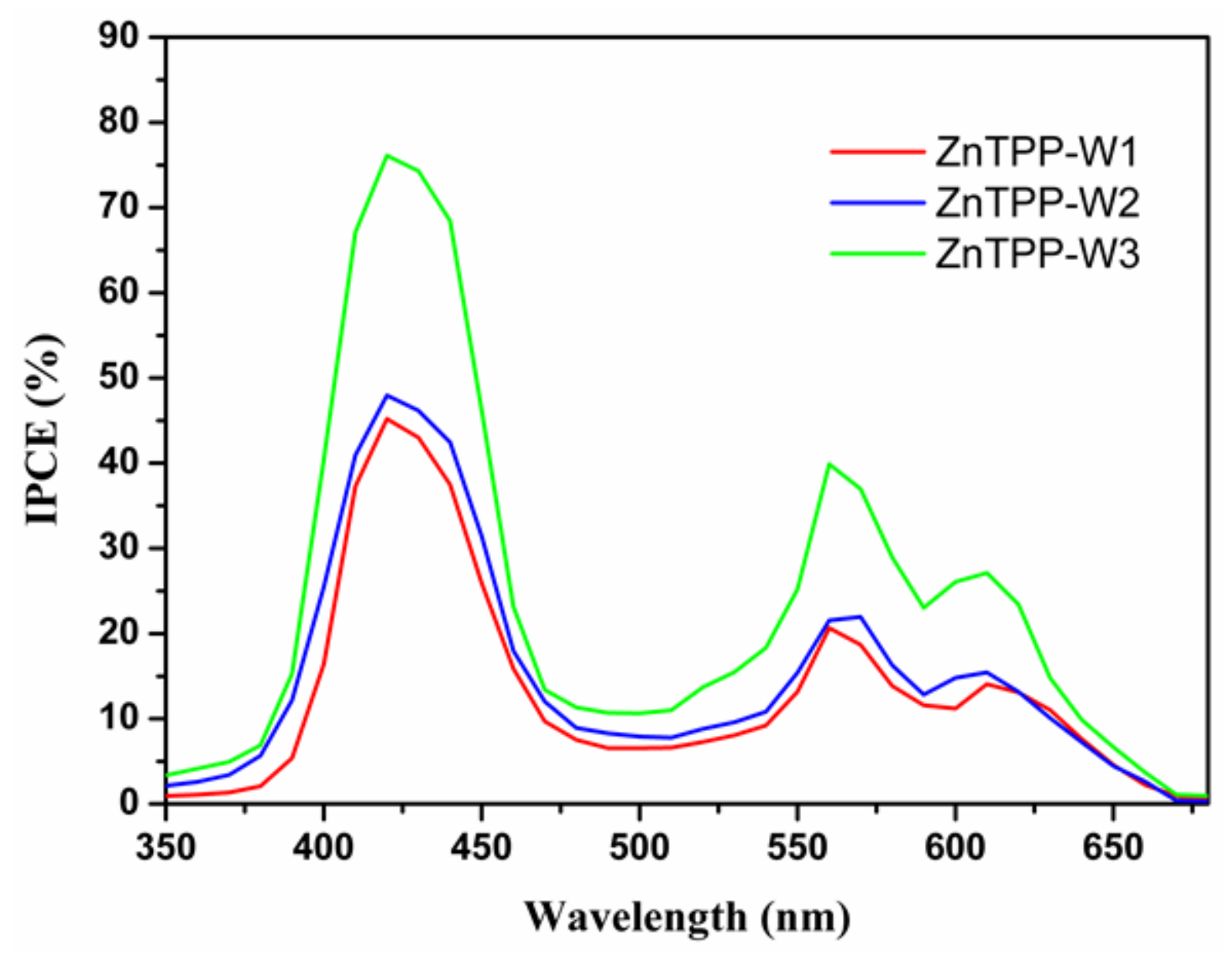

Figure 6

IPCE spectra of DSSCs based on ZnTPP-Wi $(i=1-3)$ dyes.

Figure 7

EIS spectra of DSSCs based on porphyrin dyes: (a) Nyquist plots in the dark (b) Bode phase plots in the dark (c) The equivalent circuit

Supplementary Files 
This is a list of supplementary files associated with this preprint. Click to download.

- Scheme1.png

- Scheme2.png

- Scheme3.png

- Supplementarymaterial.doc 